36 (1) | 2007

Miradas cruzadas sobre la influencia intelectual, cultural y científica entre Perú y Francia

\title{
La presencia francesa en la economía y la sociedad peruanas: un marcado desequilibrio a inicios del siglo XXI
}

La présence française dans l'économie et la société péruviennes: un déséquilibre marqué au début du XXI siècle

The French presence in the Peruvian economy and society: a clear contrast at the beginning of the 21st century

\section{Henri Godard}

\section{(2) OpenEdition}

\section{Journals}

Edición electrónica

URL: http://journals.openedition.org/bifea/4688

DOI: 10.4000/bifea.4688

ISSN: 2076-5827

\section{Editor}

Institut Français d'Études Andines

\section{Edición impresa}

Fecha de publicación: 8 mayo 2007

Paginación: 137-158

ISSN: 0303-7495

\section{Referencia electrónica}

Henri Godard, «La presencia francesa en la economía y la sociedad peruanas: un marcado desequilibrio a inicios del siglo XXI », Bulletin de l'Institut français d'études andines [En línea], 36 (1)। 2007, Publicado el 08 mayo 2007, consultado el 01 diciembre 2020. URL : http:// journals.openedition.org/bifea/4688; DOI : https://doi.org/10.4000/bifea.4688

Les contenus du Bulletin de l'Institut français d'études andines sont mis à disposition selon les termes de la licence Creative Commons Attribution - Pas d'Utilisation Commerciale - Pas de Modification 4.0 International. 


\title{
La presencia francesa en la economía y la sociedad peruanas: un marcado desequilibrio a inicios del siglo XXI
}

\author{
Henri Godard*
}

\begin{abstract}
Resumen
La huella de Francia ha sido particularmente nítida en el Perú en los campos de la cultura, de la ideología política, de las ciencias y de los descubrimientos, del urbanismo, de la arquitectura y de la vida cotidiana. Esta sigue estando presente en algunas disciplinas científicas (sociología, antropología, etc.), aunque se vea mellada por las corrientes anglosajonas. En cambio,el rol marginal de Francia en el comercio con el Perú y en las inversiones extranjeras realizadas en este país es histórico. El tema central al que esta contribución pretende aportar algunos elementos de respuesta puede expresarse así: si la influencia económica de Francia es inversamente proporcional a su presencia cultural y científica del siglo XVI al siglo XX —o por lo menos hasta el siglo XIX—, iasistimos a un desquite en el comercio y en las inversiones a comienzos del siglo XXI? Parte de la respuesta se revela en el título de este artículo. Si la presencia económica de Francia en el Perú no es determinante; en cambio, su influencia cultural y científica, que es mucho más difícil de cuantificar, sigue siendo marcada.
\end{abstract}

Palabras clave: Perú, Francia, economía, cultura, investigación científica

\section{La présence française dans l'économie et la société péruviennes : un déséquilibre marqué au début du XXI"e siècle}

\section{Résumé}

L'empreinte de la France a été particulièrement nette au Pérou dans les champs de la culture, de l'idéologie politique, des sciences et des découvertes, de l'urbanisme, de l'architecture et de la vie quotidienne. Elle est toujours présente dans certaines disciplines scientifiques, même si elle est battue en brèche par les courants anglo-saxons. En revanche, la faiblesse de la France dans le commerce avec

Instituto Francés de Estudios Andinos (IFEA). E-mail: hgodard@ifea.org.pe

El autor agradece los distintos servicios de la Embajada de Francia en el Perú, la Alianza Francesa, el Colegio Franco Peruano y el IRD que le facilitaron el acceso a documentos internos, permitiéndole la redacción de este artículo. 
le Pérou et les investissements étrangers réalisés dans ce pays est historique.La question centrale à laquelle cet article prétend apporter quelques éléments de réponse peut s'exprimer ainsi : si l'influence économique de la France est inversement proportionnelle à sa présence culturelle et scientifique du $X V l^{e}$ au $X X^{e}$ siècle —ou du moins jusqu'au XIXe-, assiste-t-on à un rattrapage du commerce et des investissements à l'aube du XXI"e siècle? Une partie de la réponse est d'ailleurs révélée dans le titre de cet article. Si la présence économique de la France au Pérou reste faible, son influence culturelle et scientifique, beaucoup plus difficile à quantifier, reste marquée.

Mots clés : Pérou, France, économie, culture, recherche scientifique

\title{
The French presence in the Peruvian economy and society: a clear contrast at the beginning of the 21 st century
}

\begin{abstract}
The stamp of France has particularly been marked in Peru in the areas of culture, political ideology, sciences and discoveries, urbanism, architecture and daily life. This is always evident in some scientific disciplines despite of having less influence than Anglo-Saxon trends. On the other hand, the weakness of France trade with Peru and French investments in this country is historic. The central issue to which this article offers some brief replies can be expressed in the following terms: if the economical influence of France is inversely proportional to its cultural and scientific presence from the 16th to 20th century - or at least until the 19st century - do we assist by catching up with trade and investments at the beginning of the 21st century? If the economical presence of France in Peru is weak, its cultural and scientific influence, more difficult to quantify, remains clearly marked.
\end{abstract}

Key words: Peru, France, economy, culture, scientific research

Las conferencias presentadas durante el coloquio La presencia francesa en el Perú pusieron énfasis sobre las migraciones de los franceses al Perú y sobre la influencia francesa que ha marcado a este país y sus habitantes desde el siglo XVIII. La huella de Francia ha sido particularmente nítida en los campos de la cultura, de la ideología política (movimiento de ideas, influencia de la Revolución Francesa y de los grandes pensadores), de las ciencias y de los descubrimientos (viajeros franceses, misiones y expediciones), del urbanismo (elaboración de los planos de Lima del siglo XVII al siglo XIX), de la arquitectura (importación y reinterpretación de los estilos arquitectónicos del siglo XIX en los años 1930) y de la vida cotidiana (fotografía, moda, cafés y terrazas, cocina). Ésta sigue estando presente en algunas disciplinas científicas (sociología, antropología, etc.), aunque se vea mellada por corrientes anglosajonas.

En cambio, los aspectos económicos y comerciales han sido eludidos pues si bien los intelectuales franceses estuvieron muy presentes, no ocurrió lo mismo con los hombres de negocios. No se trata de una omisión de parte de los organizadores del coloquio sino más bien de la expresión de la escasez recurrente de intercambios comerciales entre ambos países así como de inversiones francesas en el Perú1. Exagerando un poco, parece que los peruanos, y la mayoría de los latinoamericanos en general, consideran a los franceses como un pueblo más dotado para desarrollar teorías y mezclar ideas que para «hacer negocios»... salvo cuando se trata de productos suntuosos o gastronómicos. En este artículo vamos a mostrar que esta visión,

1 Ver, por ejemplo, Novak (2005: 218-219, 228-229, 267-270) quien analiza esta situación desde los años 1960. 
sin duda muy caricaturesca, no está del todo desprovista de fundamento. El tema central al que esta contribución pretende aportar algunos elementos de respuesta puede expresarse así: si la influencia económica de Francia es inversamente proporcional a su presencia cultural y científica del siglo XVI al siglo XX $-\mathrm{O}$ por lo menos hasta el siglo XIX—, iasistimos a un desquite en el comercio y en las inversiones a comienzos del siglo XXI? Parte de la respuesta se revela en el título de este artículo.

Aunque a menudo se trata de fuentes dispersas e incompletas, bastan para mostrar el rol limitado de Francia en 2004 y 2005 en el comercio exterior del Perú y la escasez de inversiones francesas. En cambio, Francia, que se basa por un lado en implantaciones culturales y científicas francesas y franco peruanas que gozan de buena reputación y por otro lado en los servicios cultural y universitario de la Embajada de Francia, conserva una influencia innegable en la cultura, la enseñanza, la formación y el desarrollo de proyectos de investigación aplicada.

El rubro que trata del comercio y de las inversiones se basa esencialmente en las fichas de síntesis y los documentos internos elaborados por la Misión Económica de la Embajada de Francia en Lima. Aunque los ficheros puestos a nuestra disposición son exhaustivos, estos solo toman en consideración la implantación y/o la participación de las empresas francesas en el Perú; no tienen en cuenta los comercios y servicios establecidos por franceses en este país (restaurantes, panaderías, agencias de viaje, hoteles, etc.). Ahora bien, a partir de estos ficheros consulares resulta muy difícil conocer a estas pequeñas empresas: por un lado, ahí se registra a las personas pero no a las actividades —su objetivo no es proporcionar datos económicos (por ejemplo, número de empleados de las empresas) - ; por otro lado, estos no son exhaustivos (cerca de $20 \%$ de los franceses no sienten la necesidad de inscribirse en ellos). Además, resulta imposible hacer el cruce de la base de datos de la misión económica con la base de datos del servicio consular, la misma que registraba 174 «artesanos, comerciantes, directores de empresas» de nacionalidad francesa que vivían en el Perú en 2005 — de los cuales 140 en la aglomeración de Lima y 34 en provincias2-.

La sección relativa a la influencia cultural y científica de Francia reposa sobre los documentos y los datos estadísticos proporcionados por la Alianza Francesa, el Servicio Cultural de la Embajada de Francia, el Colegio Franco Peruano, el Instituto de Investigación para el Desarrollo (IRD) y el Instituto Francés de Estudios Andinos (IFEA). Si bien algunos ficheros están disponibles en los sitios Internet de estas instituciones, numerosos informes, fichas y boletines consultados son de uso interno ${ }^{3}$.

\section{EL ROL MARGINAL DE FRANCIA EN LA ECONOMÍA PERUANA}

Las figuras 1 y 2 ponen en evidencia la debilidad de Francia en el comercio con el Perú y en las inversiones extranjeras realizadas en este país. En efecto, Francia no logra despegar y aprovechar los buenos resultados que muestra la economía peruana desde fines de los años 1990; a pesar de los esfuerzos de la misión económica de Lima, Francia se sitúa en la cola del pelotón de países que comercian con el Perú e invierten en él4.

\section{1. El peso modesto de Francia en el comercio exterior}

No obstante la buena salud mostrada por la economía peruana desde 2002, que induce una fuerte alza de las importaciones en razón del crecimiento del PIB, las exportaciones francesas

\footnotetext{
2 Ver la bibliografía.

3 Ver la bibliografía.

${ }^{4}$ La mayor parte de las informaciones han sido extraídas del sitio de la Misión Económica (http:missioneco.org.perou) y del de la SUNAT, institución peruana encargada de recaudar impuestos (www.sunat.gob.pe/).
} 
destinadas al Perú han disminuido regularmente desde hace una década. El Perú ha conocido una tasa promedio anual de crecimiento económico superior a $5 \%$ desde 2002, cuando era tan solo de 1,2\% entre 1998 y 2001 (periodo de disturbios políticos y de crisis bancaria); alcanzó 6,7 \% en 2005 y debería acercarse a $5 \%$ en 2006. Estas buenas performances de la economía y de las finanzas peruanas se explican por la política económica ortodoxa llevada por el Perú y el manejo adecuado de la deuda, que representaba $38 \%$ del PIB en 2005. Este dinamismo permite que los mercados y los inversores tengan confianza en el Perú; sin embargo, este crecimiento que reposa sobre la estructura tradicional de los intercambios en un país en desarrollo (exportaciones de productos primarios e importaciones de productos petroleros, de bienes intermedios, de equipo y de consumo) es frágil y no se traduce en una reducción de las desigualdades sociales y en la implementación de una verdadera política de desarrollo.

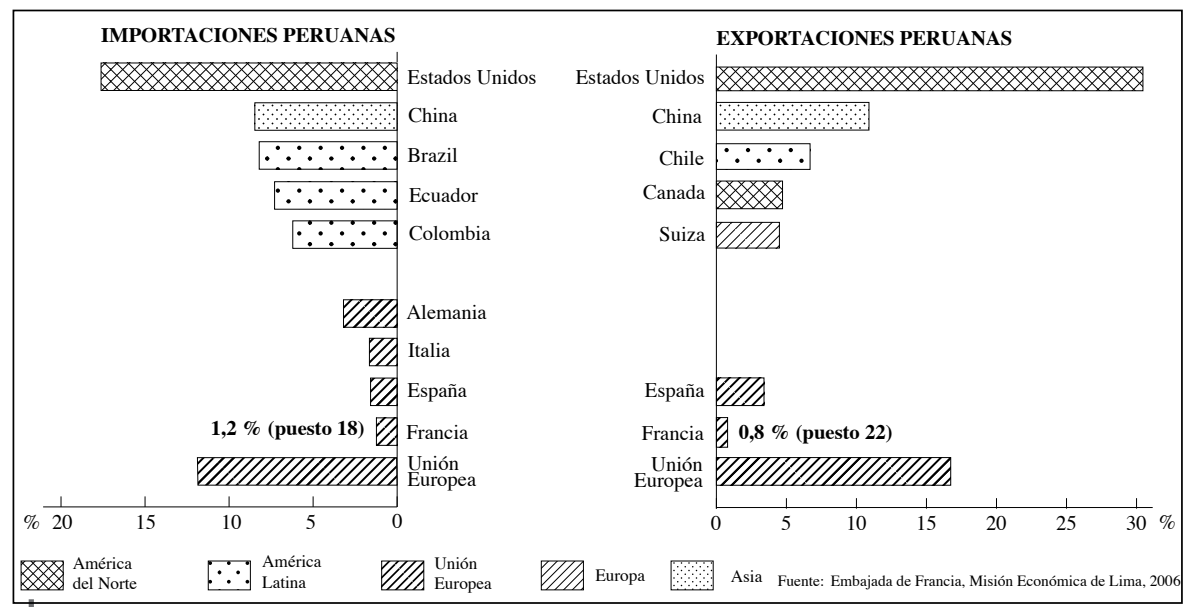

Figura 1 - El peso reducido de Francia en el comercio exterior del Perú (2005)

La multiplicación por 2,5 de las importaciones peruanas entre 2001 y 2005 no ha beneficiado a Francia. Mientras que las importaciones peruanas pasaban de 7000 a 12000 millones de dólares (+ $71 \%)$, las exportaciones francesas al Perú caían de 146 a 107 millones de dólares entre 2001 y 2005 (- 27 \%). La situación de las importaciones hechas por Francia no es mejor. Si las exportaciones peruanas progresaron entre 2001 y 2005, pasando de 7000 a 17000 millones de dólares $(+143 \%)$, las importaciones francesas del Perú permanecieron relativamente estables en el transcurso de los diez últimos años: han variado entre un mínimo de 156 millones de dólares en 2003 y un máximo de 200 millones de dólares en 2005 (progresión de 28 \% en relación a 2004). Desde 2001 el Perú registra una mejora sostenida de su saldo comercial: la tasa de cobertura, positiva desde 2002, ha pasado de $97 \%$ a $143 \%$ entre 2001 y 2005 y debería ser del orden de $130 \%$ en 2006. Sin embargo, el saldo francés no ha dejado de degradarse pues pasó de 29 millones de dólares en 2003 a 37 en 2004 y a 94 en 2005; la tasa de cobertura no ha dejado de declinar (76 \% en 2003, $70 \%$ en 2004 y $53 \%$ en 2005).

En 1998, las exportaciones francesas al Perú se elevaban a 179 millones de dólares. Entre 2003 y 2004 pasaron de 119 a 109 millones de dólares (-9 \%) y entre 2004 y 2005 bajaron en un 2 \% más. Esta regresión se explica principalmente por la casi ausencia de los grandes grupos franceses en los proyectos peruanos de infraestructura de gran envergadura y por el diferencial entre el euro y el dólar. En 2005, en la lista de proveedores del Perú, Francia ocupaba la posición 18 y detentaba tan solo 1,2 \% de parte del mercado, por delante de la India (fig.1). La estructura de las exportaciones francesas y su evolución reciente por rubros son preocupantes: si bien los productos intermedios representaban $55 \%$ de las exportaciones en $2005(+11 \%$ en relación a 2004), desde hace 4 años se constata un importante retroceso de la venta de productos acabados 
(bienes de equipo —maquinaria especializada, máquinas destinadas a la industria textil y a la fabricación de papel- y bienes de consumo). Esta situación da cuenta de la decadencia de las exportaciones de las industrias francesas de punta y de las unidades de producción de bienes de consumo (- 64 \% para los productos textiles) al Perú y, en cambio, del dinamismo de otros países de América Latina o de otras regiones del mundo (fig. 1). Los Estados Unidos, primer proveedor del Perú (17,7\% de las importaciones) retrocede ligeramente desde 2002, en valor relativo, mientras que China pasa a ser el segundo exportador hacia el Perú (+13\% entre 2004 y 2005). Les siguen Brasil, Colombia y Ecuador. La parte de las dos organizaciones económicas regionales, que aseguraban cerca de $34 \%$ de las importaciones peruanas en 2005, permanece estable: si el peso de la Comunidad Andina (CAN), que enfrenta preocupantes problemas desde la decisión de Venezuela de retirarse de ella, ha disminuido entre 2004 y 2005 (18,6 \% contra 22,4 \%), el del MERCOSUR ha progresado ligeramente (15\% contra 13,6 \%). Por último, aunque en valor absoluto las exportaciones de la Unión Europea progresan ligeramente desde fines de los años 1990, estas disminuyen regularmente en valor relativo: la parte de la Unión Europea representaba $11,8 \%$ de las importaciones peruanas en 2005 (1 478 millones de dólares) contra $12 \%$ en 2004 (1 206 millones) y $14 \%$ en 2000 (1 034 millones).

La situación de las importaciones francesas no es mejor. En 2005, estas representaron tan solo $0,8 \%$ del total de las exportaciones peruanas, lo que colocaba a Francia en la posición 22, delante de Finlandia. Es necesario pues relativizar el crecimiento de $28 \%$ entre 2004 y 2005 puesto que se trata de valores muy pequeños (comparar los 181 millones de dólares de compras de productos peruanos por Francia con los más de 5 mil millones de dólares comprados por los Estados Unidos, primer cliente del Perú por delante de China) y que la mejora solo es marginal. Signo de la difícil integración regional, la CAN y el MERCOSUR continúan siendo clientes de segunda zona: en 2005, La Comunidad Andina representaba 6,4\% de las exportaciones peruanas, o sea aproximadamente el peso de Chile, tercer cliente del Perú; con $3 \%$, la parte del MERCOSUR era inferior a la de Suiza. Si bien la Unión Europea absorbía aún 16,7 \% de las exportaciones peruanas, su parte había disminuido en cerca de 32 \% en relación al año 2004. Dentro de ella, Francia está lejos, detrás de España que compra cuatro veces más al Perú (3,3 \%), Alemania o Reino Unido.

Sin embargo, las relaciones comerciales entre los dos países están subevaluadas, en particular las exportaciones. En efecto, en el marco de la globalización económica, numerosas empresas francesas exportan al Perú a través de otros países, esencialmente latinoamericanos, en donde están implantadas sus filiales; es el caso, por ejemplo, de los vehículos franceses fabricados en Brasil y en Argentina. El valor de estas exportaciones, no consideradas en las estadísticas comerciales entre Francia y Perú, sería equivalente al de las exportaciones que sí están contabilizadas. La parte de Francia en las importaciones peruanas sería entonces del orden de 2,5 \% y no 1,2 \%. En menor medida, las importaciones francesas están igualmente subevaluadas (semiproductos, sobre todo mineros). Aunque esta subestimación debe ser tomada en consideración para dar cuenta de la realidad de los intercambios entre los dos países, hay que reconocer que ello no cambia fundamentalmente la situación de Francia en el Perú. Por un lado, el nivel del comercio entre los dos países es poco significativo; por otro lado, se ignora en qué proporciones las exportaciones y las importaciones de los otros países también se ven afectadas por esta subestimación inducida por la globalización económica y la internacionalización de los intercambios.

Desde comienzos del siglo XXI, se asiste a una reestructuración geográfica del comercio peruano: peso acrecentado de los países emergentes latinoamericanos — por lo menos de las exportaciones hacia el Perú- y asiáticos; aumento de las ventas y retroceso de las compras de los Estados Unidos desde 2002; retroceso de los «viejos» países europeos. Si bien Francia no constituye una excepción en el seno de la Unión Europea, sí se caracteriza por la escasez de sus relaciones comerciales con el Perú. El peso de Francia en las inversiones extranjeras directas (IED) es igualmente modesto. 


\section{2. La escasez de las inversiones francesas en el Perú}

Desde los años 1990, las IED han progresado mucho gracias a las medidas liberales implementadas por las autoridades peruanas. Si entre 1993 y 2005 las IED pasaron de 1640 a 14280 millones de dólares (multiplicación por 9), las de Francia, ya escasas —eran inferiores a $5 \%$ del total de las IED en 1993-, han disminuido significativamente. Pasaron de 461 a 28 millones de dólares entre 2003 y 2005. Esta caída brutal se explica por la venta al grupo italiano Intesa-BCl de la participación que detentaba el banco Sudameris en el capital del banco Wiese Sudameris.

El stock de inversiones francesas está subevaluado. Por un lado, las estadísticas proporcionadas por la agencia de promoción de la inversión privada en el Perú (Proinversión), encargada, entre otros, de registrar las IED y de manejar la base de datos, son incompletas: en efecto, si bien la legislación peruana obliga a las empresas extranjeras a registrar las IED, ésta no prevé plazos para su inscripción. Es posible declarar de una sola vez las IED realizadas en el transcurso de varios años. Por otro lado, las IED realizadas por empresas extranjeras cuya sede regional está establecida en un país diferente que el Perú no son tomadas en cuenta a título de su país de origen; en 2004, se estimaba en 145 millones de dólares las IED francesas efectuadas a partir de un tercer país. Fuera del hecho que estos disfuncionamientos afectan al conjunto de las IED, y no solamente a aquellas provenientes de Francia, cabe señalar que la porción de Francia en las IED es marginal, sea cual fuere el conjunto considerado. Si solo se toma en cuenta a las IED oficialmente registradas, esa porción se eleva a $0,2 \%$; si se considera al conjunto de las IED, apenas supera el $1 \%$.

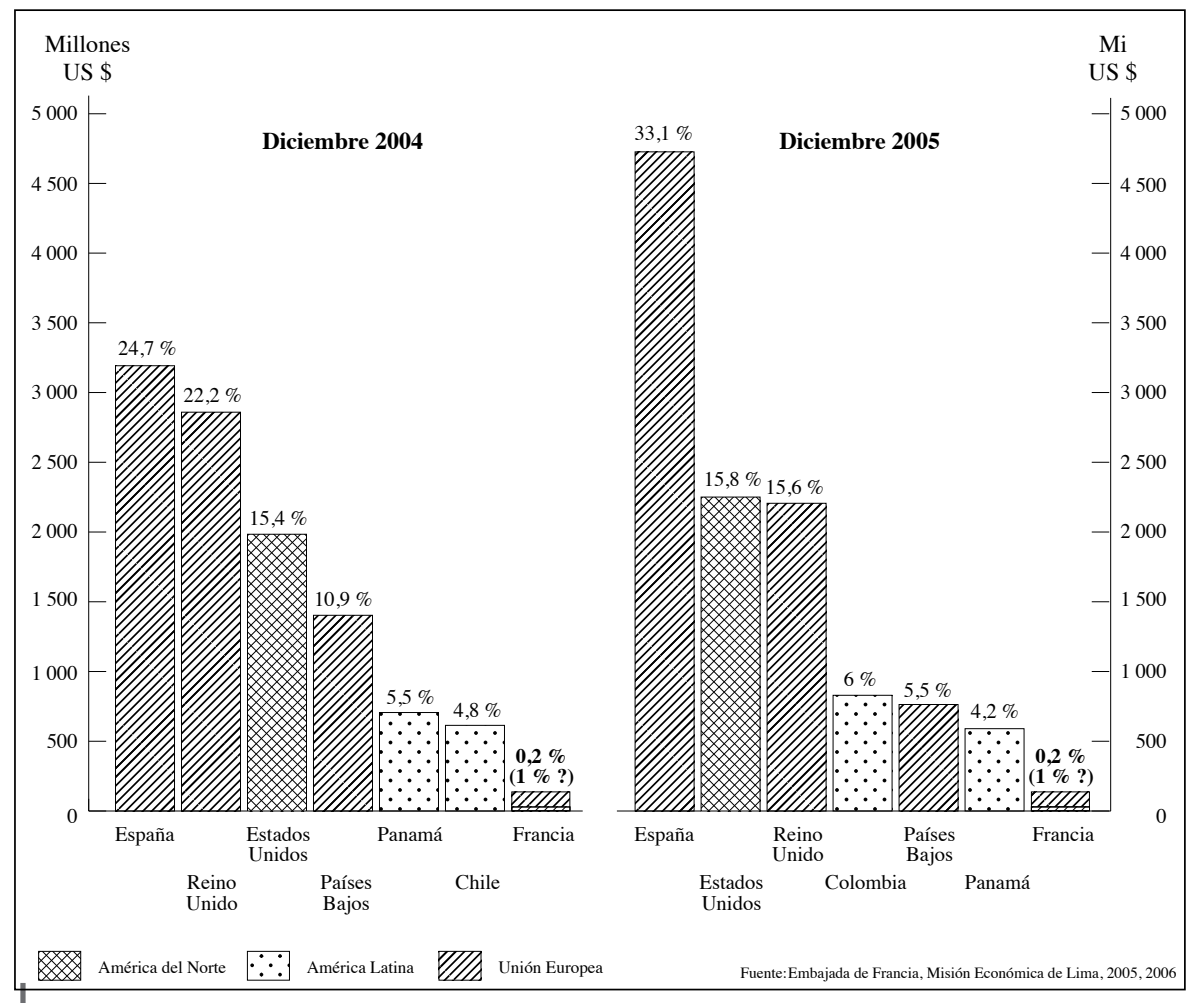

Figura 2 - La poca importancia de las inversiones francesas en el Perú (2004 y 2005) 
Después de una tasa de crecimiento sostenida de la IED en el Perú entre 1993 y 2000 (más de $10 \%$ anual), esta se ha calmado a partir de inicios del siglo XXI (3\% anual en promedio). La figura 2 muestra la evolución de la distribución geográfica de las IED entre 2004 y 2005. Si su crecimiento ha sido débil $(+2,8 \%)$, el de las inversiones francesas ha sido más marcado; el stock de IED oficialmente registradas ha pasado de 26,7 a 28 millones de dólares, es decir una tasa de crecimiento un poco menor a $5 \%$. En 2005 los tres primeros países inversores detentaban cerca de $65 \%$ de las IED realizadas en el Perú, experimentando un ligero aumento en relación a 2004. Se constata que la porción de España, primer país inversor, se dispara, pasando de $25 \%$ a más de $33 \%$ (+34 \%) y que los Estados Unidos han superado al Reino Unido.

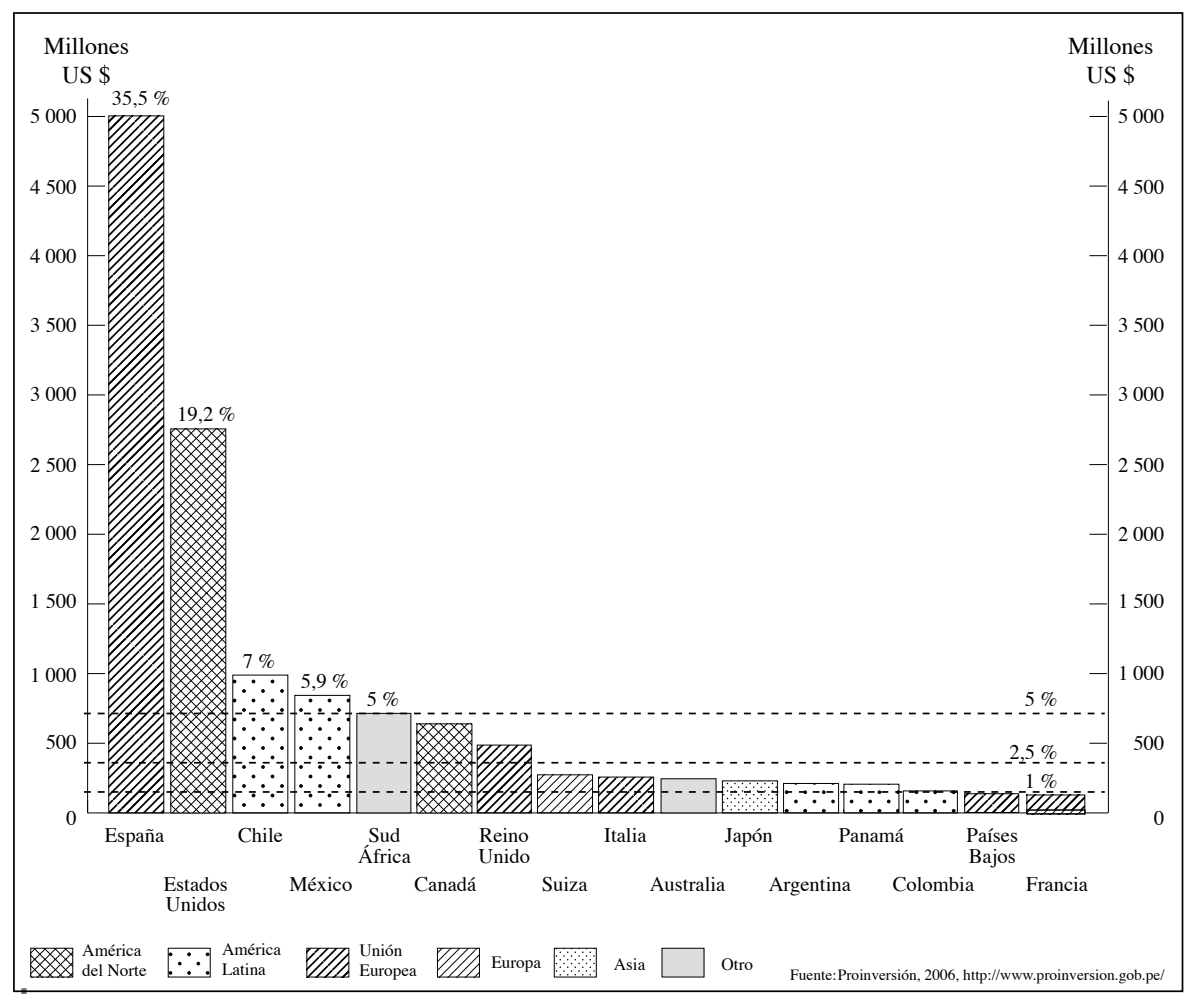

Figura 3 - La repartición de los IED en el Perú según la localización de la casa matriz (2005)

Al censar a las IED en función de la localización de la casa matriz, la distribución geográfica cambia (fig. 3). Las porciones de España y de los Estados Unidos aumentan (cerca de $55 \%$ los dos juntos) y la distancia entre el segundo y tercer país, Chile, es muy importante, pues este país sudamericano solo posee un tercio de las IED realizadas por los Estados Unidos. Las inversiones del conjunto de los países latinoamericanos son inferiores a las de Estados Unidos (17,5 \% contra 19,2 \%). En cuanto a Francia, que ocupa el puesto 14 entre los países inversores detrás de los Países Bajos y delante de China, su porción se estanca.

Los sectores económicos en los cuales las IED son más importantes son, por orden de importancia: comunicaciones, finanzas, industria, minas y energía. España tiene cerca de $85 \%$ de las IED en telecomunicaciones gracias a la empresa Telefónica y más de $50 \%$ en el sector financiero. Los Estados Unidos intervienen principalmente en las minas (más de $35 \%$ ), en la energía (más de $25 \%$ ) y las finanzas (más de $10 \%$ ). Reino Unido posee cerca de $40 \%$ de las IED en el sector 
minero y más de $15 \%$ en banca y finanzas. Unas cuarenta empresas francesas tienen una filial en el Perú. Sin embargo, son pocas las que han instalado una unidad de producción u oficinas con personal numeroso: a menudo ocupan un local y cuentant con algunos asalariados. Solamente cinco empresas emplean más de 30 personas: Arcopa (pesca y transformación de productos del mar congelados), instalada en Perú (Paita) desde 2002 emplea a aproximadamente 800 personas; Devanlay, que fabrica y exporta productos textiles Lacoste hacia Estados Unidos desde 2001, emplea 350 obreros aproximadamente; el grupo Accor, implantado en el mercado peruano desde 2000, ha abierto dos hoteles en Lima y Cusco que emplean una centena de asalariados; por último, las empresas, Charles Garnier (joyería), instalada desde 2005, y el banco BNP Paribas, establecido en Lima desde mediados de los años 1990, emplean menos de 50 personas (fig. 4).

Si bien las inversiones francesas progresan, marginalmente, desde hace algunos años, se puede esperar que los buenos resultados de la economía peruana y la puesta en marcha de grandes proyectos de infraestructura (transportes urbanos, red vial, modernización de los puertos, fábrica de licuefacción de gas) serán aprovechados por las empresas francesas. La escasa presencia económica de Francia en el Perú se debe al hecho que no participó en el gran movimiento de privatización de las empresas peruanas a partir de 1993 (telecomunicaciones, aeropuerto de Lima...), que tiene un peso modesto en el sector minero, uno de los más importantes en las exportaciones peruanas, y que no ha logrado, por lo menos hasta 2005, ganar licitaciones en el sector de las infraestructuras (transportes, agua, etc.). En cambio, la influencia cultural y científica de Francia en el Perú, que es mucho más difícil de cuantificar, sigue siendo marcada.

\section{EL PESO CULTURAL Y CIENTÍFICO DE FRANCIA}

Los lazos culturales y científicos que unen al Perú y a Francia son antiguos. En 1535, fue publicado en Lyon el primer documento en francés referente al Perú (Nouvelles certaines des îles du Pérou). En 1667, Pierre Daniel Huet terminó su manuscrito Diana de Castro ou le faux Inca: por primera vez, la acción de una novela —o más bien de una novela seudo histórica- escrita en francés se desarrollaba en parte en el Perú. En los siglos XVIII y XIX, las misiones científicas y las expediciones francesas se sucedieron. Sin embargo, en el siglo XIX, y sobre todo a partir de mediados del siglo $X X$, la cooperación cultural y científica se reforzó entre ambos países gracias a la instalación permanente de instituciones francesas y francoperuanas $y$ al desarrollo de los servicios culturales de la Embajada de Francia. Tres subconjuntos, cuya distribución geográfica aparece sobre la figura 4, se individualizan. El primero reúne a los establecimientos franco peruanos de enseñanza del francés; el segundo agrupa a los institutos franceses de investigación que trabajan en estrecha cooperación con contrapartes públicas o privadas peruanas; el tercero, que desempeña un rol político y cultural esencial, apoya las acciones de los anteriores, trabaja en la promoción del idioma francés y alienta a los peruanos a proseguir sus estudios universitarios en Francia.

\section{1. El rol «tradicional» del Colegio Franco Peruano y de la Alianza Francesa}

En 2006, Francia disponía de una red conformada por 430 establecimientos escolares franceses en el extranjero (escuelas, colegios y liceos) cuya enseñanza está homologada por el Ministerio de Educación Nacional francés. Presentes en más de 130 países, estos establecimientos garantizan la escolarización de más de 240000 alumnos, de los cuales 80000 son franceses. La Agencia de Enseñanza Francesa en el Extranjero (AEFE), establecimiento público nacional de carácter administrativo dependiente del Ministerio de Relaciones Exteriores, administra 252 establecimientos (160 000 alumnos, de los cuales 71000 son franceses). La mayoría de estos establecimientos son de carácter privado y de derecho local. 


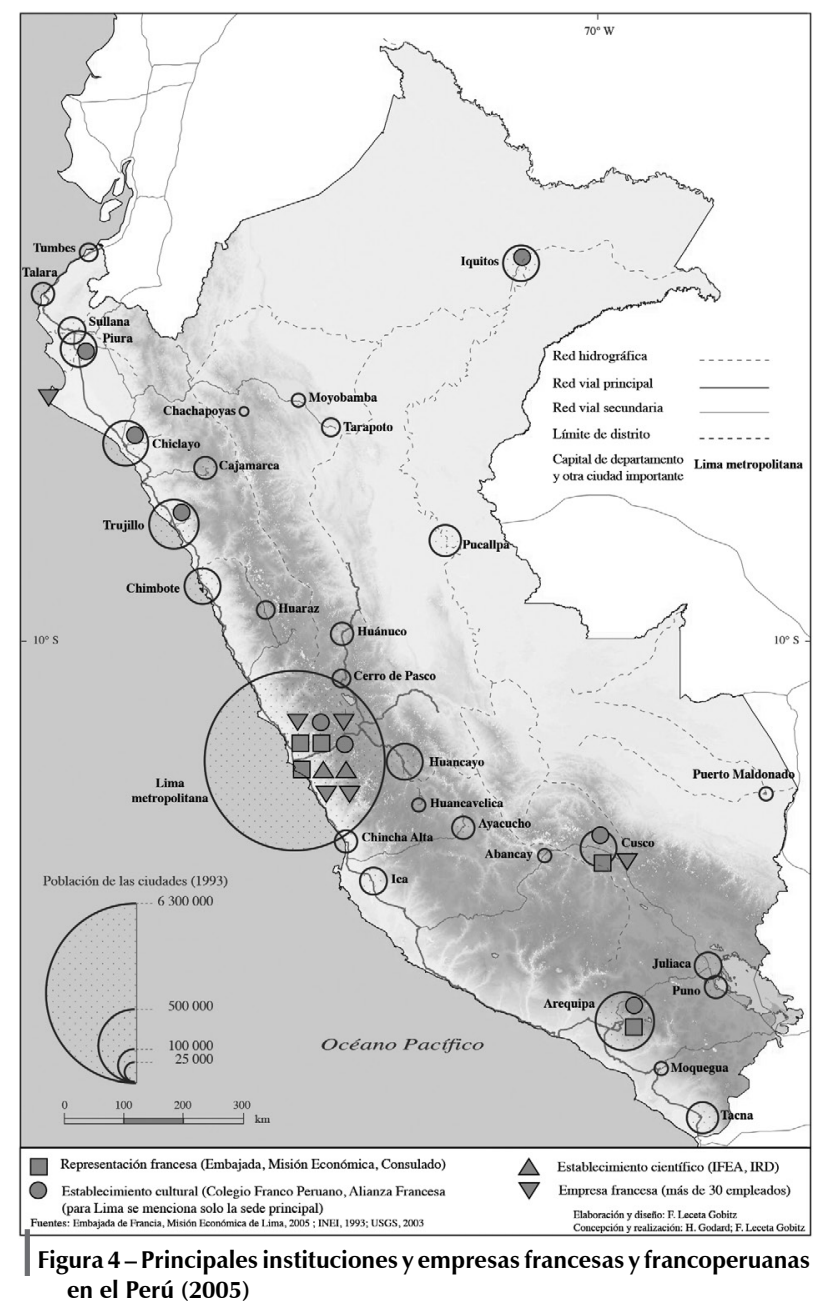

Fundada en 1950 en el distrito de Miraflores, la Escuela Nueva, hoy Colegio Franco Peruano, se instaló en sus nuevos locales construidos en Monterrico (distrito de Surco) en 1959. Establecimiento de derecho privado peruano, este colegio es reconocido a la vez por los ministerios peruano y francés de Educación Nacional. Este establecimiento experimental bicultural y bilingüe imparte el programa de enseñanza del Ministerio de Educación Nacional francés. Abierto, entre otros, a los alumnos de nacionalidad francesa residentes en el extranjero, el colegio dispensa una enseñanza conforme a los programas, a los objetivos pedagógicos y a las reglas de organización aplicables en Francia en los establecimientos de enseñanza pública. El colegio prepara a los alumnos para los mismos exámenes y diplomas que pasan los alumnos de los establecimientos públicos en Francia, permitiendo así que se presenten al Bachillerato en el Cono Sur que reúne al Perú, Argentina, Bolivia, Brasil, Chile, Paraguay y Uruguay. El colegio dispensa del mismo modo algunos programas, en lengua castellana, del Ministerio de Educación peruano (historia, geografía, literatura, lengua y educación cívica), lo que da la posibilidad a los alumnos de terminar sus estudios en Quinto Grado de Secundaria, equivalente a Seconde en el sistema escolar francés. 
El Colegio Franco Peruano, único establecimiento de la red de la AEFE en el Perú, acoge a alumnos de cualquier nacionalidad cuyas familias desean que sigan una educación francesa. Sin embargo, el diálogo entre cultura francesa y cultura peruana permite a los niños recibir una formación bicultural. Sobre un terreno de tres hectáreas y rodeado de jardines, el establecimiento tiene dieciséis edificios que albergan las aulas de inicial, primaria y secundaria así como las oficinas administrativas y los servicios. Las nuevas tecnologías en la enseñanza están representadas en las salas de informática y los laboratorios. Por último, las infraestructuras culturales y deportivas (teatros, centro de documentación que reúne 16000 obras, canchas de fútbol, basket y vóley) completan el conjunto.

En aumento regular desde hace cuatro años, el número de alumnos llega a cerca de 850, escolarizados desde inicial hasta el bachillerato (año escolar 2006). Abierto de manera amplia sobre la sociedad peruana, 60 \% de los alumnos del Colegio Franco Peruano son peruanos; 33 \% son franceses y finalmente los de otra nacionalidad representan un $7 \%$. En 2006, el colegio empleaba a más de 70 profesores nombrados, residentes y locales y el personal no enseñante está conformado por más de 40 personas (administración, documentación, servicios, etc.).

Este establecimiento, que goza de una excelente imagen en el Perú, obtiene resultados notorios durante las evaluaciones y exámenes. Los colegios de la red de la AEFE obtienen una tasa de éxito particularmente elevada en el bachillerato: $94 \%$ de los candidatos obtuvieron el diploma en el año 2005. Los resultados del Colegio Franco Peruano son superiores a este promedio. En el transcurso de los siete últimos años, el porcentaje de éxito no ha sido jamás inferior a $94 \%$ y en 2001, 2002, 2005 y 2006, 100 \% de los candidatos obtuvieron su diploma. En 2005, 64 \% de los 36 candidatos alcanzaron una mención contra $58 \%$ para el conjunto de los establecimientos administrados directamente por la AEFE. Finalmente, $33 \%$ de los candidatos obtuvieron su bachillerato con la mención «Muy bien» o «Bien» (contra $25 \%$ para el conjunto de los colegios de la red). Estos resultados dan fe de la calidad de la enseñanza en este colegio siendo numerosos los alumnos que después del Bachillerato integran prestigiosos establecimientos franceses y prosiguen con éxito sus estudios en universidades francesas y peruanas.

Por último, a semejanza del conjunto de establecimientos franceses de la red de la AEFE, el Colegio Franco Peruano ha implementado un proyecto de establecimiento que está estructurado alrededor de tres grandes ejes: promoción de la comunicación y de la cultura, coherencia de las enseñanzas y éxito de los alumnos; reflexión sobre la enseñanza del francés y de las lenguas. Los otros elementos del dispositivo cultural y científico francés y franco peruano (Alianza Francesa) participan en algunas actividades desarrolladas en el marco del primer eje que permiten asegurar el alcance del colegio en la aglomeración limeña.

Otro elemento clave de la difusión del francés en el extranjero, las alianzas francesas del Perú forman parte de una red que reunía en 2004 a cerca de 1100 establecimientos instalados en 135 países. Aproximadamente 420000 estudiantes frecuentaban los cursos de las alianzas en 2004 (+ 5,4 \% en relación a 2003), de los cuales cerca de 125000 en América Latina en donde las alianzas están instaladas en 19 países. Si en esta región del mundo, Argentina agrupaba el mayor número de alianzas (71) por delante de México (48) en 2004, la Alianza Francesa de Lima 5 acogió, en 2006, el mayor número de estudiantes en el mundo (cerca de 10 000), delante de la de París. La red de las alianzas en el Perú cuenta con 5 establecimientos en Lima —el sexto será abierto en 2007- y 6 implantaciones en provincias (figura 4). El Perú y las implantaciones limeñas tienen fuerte peso en el sistema de la Alianza Francesa: el país está clasificado entre los diez primeros y Lima (el conjunto de las alianzas de la capital) está clasificada entre las cinco primeras ciudades, ya se trate de los ingresos o del número de asalariados. Los establecimientos limeños que reúnen cerca del 75 \% de los estudiantes de las alianzas en el Perú, se caracterizan

5 Cuando las 5 alianzas francesas de Lima se consideran como un todo, escribimos la Alianza de Lima. Cuando escribimos la Alianza Francesa o la Alianza Francesa de París (la sede), consideramos el conjunto del dispositivo a escala mundial. 
por una notoria tasa anual de crecimiento. El número de estudiantes ha pasado de menos de 4500 en 2001 a cerca de 11000 en 2005. Después de una progresión espectacular de los efectivos entre 2001 y 2002 (más de $70 \%$ ), la tasa media anual de crecimiento ha sido superior a 105 entre 2002 y 2005. Esta fuerte progresión de los estudiantes es dos veces superior a la tasa media de los efectivos del conjunto de los establecimientos de la Alianza Francesa en el mundo. La mayoría de las alianzas en el Perú tiene tasas de crecimiento elevadas, ya se trate de la de Arequipa, la segunda en el país en número de estudiantes (la única en superar el millar de estudiantes - más de 1200 en 2004- junto con el conjunto limeño) o las de Trujillo (cerca de 800 estudiantes) o de lquitos (más de 300 estudiantes).

La Asociación Nacional para la Propagación de la Lengua Francesa en las Colonias y el Extranjero fue creada en 1883 y al año siguiente se constituyó el Consejo de Administración de la Alianza Francesa de París, en el que figuraban ilustres personalidades literarias y científicas (Ferdinand de Lesseps, Louis Pasteur, Ernest Renan, Jules Verne, Armand Colin...). En 1884 las primeras alianzas francesas fueron creadas en España, Senegal, Mauricio y México. La alianza francesa de Lima fue fundada en 1890 por un grupo de residentes franceses en el local de los bomberos de la Bomba Francia; su sede está actualmente instalada en un antiguo convento situado en pleno corazón del distrito de Miraflores. A inicios del siglo XX, la Alianza Francesa contaba con 150 comités en Francia y 450 en el extranjero y en 1919 se abrió en París la primera Escuela Práctica de Lengua Francesa, en el boulevard Raspail: ésta, que en 1952 será rebautizada con el nombre de Escuela Internacional de Lengua y de Civilización Francesas, tenía ya 4800 estudiantes en 1930. Desde los años 1950, la red de las alianzas francesas se ha extendido considerablemente (implantación en 80 países en 1980) y se ha acelerado la modernización de los establecimientos desde comienzos del siglo XXI (instalación de centros de recursos multimedia). En el Perú se han abierto alianzas francesas en las aglomeraciones más importantes de las tres regiones geográficas del país: Cusco en 1948, Arequipa en 1953, Chiclayo, Piura y Trujillo en 1965 e Iquitos en 1990.

Las alianzas, asociaciones autónomas regidas por el derecho local cuyos recursos provienen en su mayoría de la venta de los cursos de francés, están ligadas a la Alianza Francesa de París que garantiza la coherencia del dispositivo, vela por el respeto de los estatutos, participa en reclutamiento de personal destacado puesto a la disposición de las alianzas por el Ministerio de Relaciones Exteriores francés y se encarga de hacer el seguimiento de las subvenciones que este le otorga. Las alianzas, nexo entre las culturas locales y francófonas, difunden la lengua y la cultura francesas. Su misión es tanto pedagógica (desarrollo de la enseñanza de la lengua francesa) como cultural (organización de eventos destinados a buscar, entre otros, la promoción de los artistas y de las culturas francófonas y locales).

La misión pedagógica se basa en la promoción y el aprendizaje del francés («lengua de cultura» y lengua útil en el mercado laboral); la preparación para los diplomas del Ministerio de Educación Nacional francés y de aquellos que son reconocidos por el gobierno francés; la formación inicial de los profesores de francés. La Alianza de Lima, que empleaba en 2005 más de 250 asalariados, de los cuales 133 profesores —que siguen regularmente cursos de formación continua, poseen un diploma superior de lengua francesa y muchos de ellos han estado en Francia-, y tenía cerca de 11000 estudiantes, cumple estas misiones poniendo énfasis en la formación permanente del cuerpo profesoral. Ha acogido a varios especialistas franceses y ha otorgado, con el apoyo de la Embajada de Francia, una beca de estudios a varios docentes. Estas actividades son sostenidas por una importante mediateca que ha sido renovada y reestructurada en 2005: alberga aproximadamente 17000 documentos (libros, revistas, magacines, diarios), 500 DVD y 300 CD y está equipado con lectores de DVD y computadoras conectadas a la red de Internet y al canal francés TV5. El nuevo local de La Molina, inaugurado en 2005, dispone igualmente de una mediateca consecuente.

La misión cultural es la prolongación de la misión pedagógica de las alianzas. En Lima, la calidad de las infraestructuras permite desarrollar múltiples actividades culturales: la sede limeña dispone de un auditorio, de un cineclub, de una galería de arte y de un café. En 2005, la Alianza de Lima 
presentó una veintena de obras teatrales, 10 exposiciones, 3 espectáculos de danza, unas sesenta conferencias en colaboración con la Embajada de Francia, el IFEA y la Pontificia Universidad Católica del Perú-PUCP, además de un centenar de proyecciones cinematográficas. También se organizan regularmente manifestaciones culturales y científicas (seminarios, conferencias, conciertos, espectáculos...) que permiten el diálogo entre las culturas francesas, francófonas y peruanas. La Alianza de Lima participa igualmente en la organización de eventos extra muros, como por ejemplo la Fiesta de la Música, la Velada de la Francofonía — concurso nacional de intérpretes de la canción francófona-, Pasaporte para un artista.

Las alianzas francesas mantienen también vínculos estrechos con el sistema educativo y las universidades locales. La Alianza de Lima ha firmado numerosos acuerdos de cooperación con instituciones privadas y públicas limeñas que aportan su contribución para la difusión y promoción de la lengua y la cultura francesas. Desde hace tres décadas se han estrechado los vínculos de colaboración principalmente en el campo de la enseñanza. En 2005, estaban afiliados a la Alianza de Lima 22 colegios, 9 universidades y 2 colegios profesionales - es decir más de 12000 estudiantes y 160 profesores. Finalmente, la Red de Excelencia, constituida en el año 2000, agrupa a 22 colegios limeños que otorgan una atención particular a la enseñanza del francés. Reconocidos por la Embajada, los profesores de estos establecimientos reciben apoyo pedagógico por parte de la Alianza de Lima y sus alumnos organizan numerosas manifestaciones específicas.

La Alianza de Lima desempeña también un rol de intermediario en las acciones de cooperación emprendidas entre las francesas y peruanas. La oficina de la agencia EduFrance está instalada en los locales de la sede de la Alianza de Lima. Actuando en estrecha colaboración con los ministerios franceses de Educación, de Relaciones Exteriores, de Investigación, de Cultura y de Industria, EduFrance está encargada de asegurar la promoción en el extranjero de la oferta francesa de formación y conocimiento en la enseñanza superior, de contribuir en la mejora de la recepción de estudiantes extranjeros en Francia, de ayudar a elaborar la respuesta francesa para las licitaciones internacionales. En Lima, EduFrance, que trabaja en estrecha colaboración con la mayoría de las universidades peruanas, organiza conferencias informativas y un foro anual en el que participan varias universidades francesas. Desde hace dos años, este foro se organiza también en las alianzas de Arequipa y de Trujillo, que disponen de espacios EduFrance. Al dinamizar la audiencia internacional de la enseñanza superior francesa y al facilitar la acogida de estudiantes e investigadores peruanos en Francia, la actividad EduFrance ha contribuido desde hace seis años al crecimiento del número de estudiantes peruanos en Francia (en 2004, más de 500 fueron a perfeccionar su formación en una universidad francesa).

Lugar de diálogo entre Francia y Perú, la actividad de las alianzas francesas del Perú no se resume al dinamismo de las de la capital, contrariamente a lo que este artículo dejaría suponer. Si las fuentes consultadas dan preeminencia a la Alianza de Lima, otros elementos de este dispositivo, en su escala — local o regional y no nacional—, están en pleno auge. La de Arequipa, creada en 1953, muestra gran dinamismo. Centro de examen internacional, registra una fuerte progresión del número de sus estudiantes desde hace algunos años. Centro cultural activo bien implantado en el centro histórico de la ciudad, se caracteriza por la riqueza de su centro de recursos y por su programación cultural.

Las alianzas francesas son apoyadas por el Estado francés, y por la Embajada de Francia, tanto en su funcionamiento como cuando se produce un acontecimiento excepcional. Después del terremoto de 2001 que dañó mucho la casona que ocupa la alianza francesa de Arequipa desde los años 1970, recibió un apoyo financiero del Estado francés para restaurar y consolidar las construcciones el edificio, inscrito por la UNESCO en el patrimonio mundial de bienes culturales.

Si el Colegio Franco Peruano y las alianzas francesas son los elementos de dos sistemas cuyos componentes están presentes en numerosos países del mundo, el Perú acoge dos estructuras científicas, menos representadas en el mundo, que vienen a completar el dispositivo cultural y científico francés en este país. 


\section{2. El rol científico del IFEA y del IRD}

En julio de 1988 se llevó a cabo en Lima el coloquio La investigación francesa y el Perú, cuyas actas fueron publicadas ese mismo año (Lefort et al., 1988). Este evento reunió a más de un centenar de investigadores de gran renombre, tanto franceses como peruanos. Por un lado, este coloquio permitió presentar el balance y el estado de los estudios científicos en curso. Por otro lado, puso en valor la estrecha cooperación científica entre el Perú y Francia —siendo numerosas las investigaciones efectuadas conjuntamente por investigadores de ambos países. Por último, fue una ocasión para sacar a luz los ejes científicos a privilegiar dentro del marco de una investigación aplicada, estrechamente ligada a la realidad nacional peruana y útil al desarrollo del país. Este evento reunió por primera vez a los tres actores franceses de la investigación científica (el IFEA, el Instituto Francés de Investigación Científica para el Desarrollo en Cooperación —Orstom, hoy IRD—y la Embajada de Francia) y los actores peruanos. Desde que se instalaron en el Perú, estos dos institutos han multiplicado sus actividades. La calidad y la utilidad de sus investigaciones son reconocidas más allá de las fronteras peruanas. Desde hace unos veinte años, ambos institutos han hecho modificaciones en su política científica para articularla mejor con el desarrollo y para que la formación y la difusión de los resultados científicos sea mayor.

El IRD (Orstom desde su creación en 1944 hasta 1998) es un establecimiento público francés de carácter científico y tecnológico, que funciona bajo la tutela de dos ministerios, el de Investigación y el de Cooperación. Encargado de cumplir cuatro misiones —investigación científica, peritaje y valorización, apoyo y formación, información científica-, el IRD cuenta con cerca de 2200 agentes, de los cuales 800 investigadores y 800 ingenieros y técnicos aproximadamente, y dispone de una representación en 25 países extranjeros. Los programas de investigación, centrados sobre las relaciones entre el hombre y su entorno en los países del Sur, se inscriben en el seno de seis grandes ejes:

- Riesgos naturales, climas y recursos no renovables (eje 1);

- Manejo sostenible de ecosistemas del sur (eje 2);

- Aguas continentales y costeras (eje 3);

- Seguridad alimentaria (eje 4);

- Seguridad sanitaria, políticas de salud y acceso a la atención médica (eje 5);

- Desarrollo y globalización (eje 6).

El IRD es tanto un instituto que conduce investigaciones «cuya finalidad es contribuir al desarrollo económico, social y cultural de los países del Sur» (IRD, 2006: 5) como, desde 2005, una agencia encargada de movilizar todos los elementos del dispositivo científico francés (organismos de investigación públicos y privados tanto en Francia como en los países en desarrollo, «grandes escuelas» y universidades) a favor de la investigación para el desarrollo. El IRD lleva a cabo sus proyectos de investigación en estrecha concertación y cooperación con las contrapartes científicas y técnicas de los países en desarrollo o emergentes a través de equipos «mixtos» en los cuales participan estudiantes.

El Orstom, que abrió una representación en el Perú en 1967, dio inicio a su cooperación efectuando el estudio geológico de la cordillera oriental dentro del marco de un convenio firmado con el Servicio Nacional Minero Geológico del Perú. Se tuvo que esperar hasta 1985 para que el Orstom diversifique sus acciones y responda a las múltiples demandas de cooperación formuladas por instituciones peruanas. Tres razones explican el paso de la cuasi monodisciplinariedad a la participación del Orstom en numerosos proyectos pluri e interdisciplinarios. Por un lado, a inicios de los años 1980, la nueva dirección del instituto decidió reorientar la política científica del Orstom hacia las problemáticas de desarrollo. Por otro lado, el Instituto se abrió a América Latina: cuando sus acciones estaban esencialmente centradas sobre África, el Orstom inauguró sucesivamente representaciones en Ecuador, Bolivia y Perú. Por último, eran cada vez más 
numerosas las instituciones peruanas que solicitaban la participación del Orstom en programas de investigación y de formación en los que intervenían otras disciplinas además de la geología. Así, sucesivamente, fueron destacados al Perú un especialista en ecología, luego sismólogos y finalmente, agrónomos, geógrafos, arqueólogos, etc.

En 2007, las actividades científicas del IRD en el Perú están reguladas por el acuerdo-marco firmado en 1998 entre el Instituto y el Consejo Nacional de Ciencia, Tecnología e Innovación Tecnológica (CONCYTEC). Este es el interlocutor privilegiado del IRD (definición de ejes estratégicos del desarrollo y de prioridades científicas) que legitima el conjunto de las acciones efectuadas por el Instituto en el Perú. Los convenios de cooperación firmados entre el IRD y las contrapartes peruanas (seis institutos sectoriales, cinco universidades, una ONG, tres empresas privadas) se refieren a programas de investigación de interés común y a actividades de formación y de valorización. Si bien el dinamismo de una institución no se mide por el número de sus investigadores, sin embargo este es un indicador significativo: a inicios del año 2007, el IRD tendrá 20 investigadores permanentes (contra 7 a comienzos del año 2005), una decena de ellos con permanencias de «larga duración» (3 a 6 meses) y más de quince practicantes, en su mayoría estudiantes que preparan un estudio académico. Finalmente, un centenar de investigadores, profesores, ingenieros y estudiantes peruanos participan en los programas de investigación y formación efectuados por el IRD en estrecha colaboración con las instituciones nacionales.

Las investigaciones, que privilegian la aplicación, contribuyen al desarrollo sostenible de los países y son una ayuda para la toma de decisiones de los diferentes actores nacionales. En el Perú, están en curso unos quince programas científicos (2005-2008). Si bien las ciencias de la tierra dominan, la parte consagrada a las ciencias del hombre y de la sociedad se va acrecentando. Los programas se inscriben en cinco de los seis grandes ejes del Instituto:

- En el eje 1: variabilidad climática y evolución de los glaciares; evolución, dinámica actual y estructura de los Andes; geodinámica y sistemas petroleros de las cuencas neogénas; investigación y formación sobre la vulnerabilidad y los riesgos en el medio urbano;

- En el eje 2: dinámica y evolución de diversos tipos de palmeras; insectos plagas de las plantas amazónicas;

- En el eje 3: funcionamiento biofísico-químico y ecológico del sistema de la corriente de Humboldt; climatología, hidrología, geoquímica y flujos sedimentarios en la cuenca amazónica; caracterización y valorización de la diversidad piscícola;

- En el eje 5: sustancias naturales leishmanicidas y antipalúdicas; condiciones de emergencia y de propagación del dengue; coinfección paludismo y enfermedad de Chagas en mujeres gestantes);

- En el eje 6: reconfiguración de los espacios rurales; dinámica de la pobreza; agricultura biológica, comercio equitable y desarrollo territorial.

La mayoría de estos proyectos se efectúan en un marco regional, ya se trate del enfoque espacial (Andes, Amazonía), ecosistémico (Cuenca Amazónica, sistema de la corriente de Humboldt) o de aquel que busca favorecer la integración regional (Comunidad Andina-CAN, Tratado de Cooperación Amazónica).

El campo de apoyo y formación está destinado a reforzar las capacidades de investigación de los países del Sur y favorecer su integración a escala internacional. En el Perú, los investigadores del IRD y los investigadores franceses que cumplen una misión científica de corta duración (un centenar por año), dan conferencias, participan en coloquios, dictan cursos de maestría y de doctorado en varias universidades peruanas y apoyan y/o codirigen los estudios académicos de estudiantes peruanos (tesis de maestría y de doctorado). EI IRD, que ha participado en la implementación de dos maestrías en la Universidad Nacional Mayor de San Marcos, ofrece becas de doctorado a estudiantes peruanos que realizan su trabajo académico en cotutela francoperuana y contribuye en la formación permanente de científicos, catedráticos-investigadores y técnicos de alto nivel peruanos tomando a su cargo estadías en Francia. En 2005-2006, los investigadores 
del IRD dirigen 19 doctorados (9 peruanos), 7 maestrías en universidades francesas (2 peruanos), 6 maestrías y 16 tesis de bachillerato, licenciatura o ingeniería en universidades peruanas. Por último, cada año el IRD coorganiza y/o apoya eventos científicos internacionales y coedita varias publicaciones, a veces con el IFEA. En efecto, estos dos institutos franceses, cuyos modos de actuar son específicos, llevan a cabo acciones complementarias.

Desde su creación en enero de 1948 por un pequeño grupo de profesores y de investigadores franceses, el Instituto Francés de Estudios Andinos (IFEA) definió su principal objetivo: participar en el desarrollo y en la difusión de los conocimientos sobre el mundo andino en el marco de una investigación pluridisciplinaria, de un enfoque regional —la sede del IFEA está en Lima pero su área de intervención abarca cuatro países: Perú, Bolivia, Colombia y Ecuador-y de un diálogo entre instituciones e investigadores franceses y andinos. Desde hace más de 50 años, el IFEA persigue estos principios y ha intensificado y desarrollado sus acciones sin cesar. A mediados de los años 1960, el número de investigadores aumentó, el despliegue regional se consolidó y se lanzaron grandes programas regionales pluridisciplinarios. En los años 1980, el IFEA abrió filiales en Bolivia, Colombia y Ecuador, afianzó los lazos de cooperación con la investigación francesa (Orstom y Centro Nacional de la Investigación Científica-CNRS) y con la investigación local, reforzó el campo de la formación de jóvenes científicos andinos así como su política de participación en eventos científicos y de coedición. En 1990 se construyó un local para albergar la biblioteca y se creó un banco de datos informatizado. Desde fines del año 2000, la visibilidad regional e internacional del IFEA se reforzó y se intensificaron las investigaciones referentes a las problemáticas contemporáneas (participación de los movimientos indígenas en la vida política, integración regional, recomposiciones territoriales, etc.), sin penalizar las disciplinas que fueron - y que siguen siendo - la punta de lanza de la investigación en el seno del IFEA (historia, arqueología, antropología...).

Para cumplir con sus objetivos, el IFEA, en estrecha colaboración con las instituciones de los cuatro países andinos, se basa en tres actividades complementarias: la producción de conocimientos científicos orientados hacia las ciencias del hombre y las de la tierra y de la vida; la animación científica, complemento indispensable de la investigación, con la organización de conferencias, coloquios y seminarios; la difusión de los conocimientos y el alcance del Instituto con la edición de una revista y de libros, el acceso gratuito para el público a una biblioteca reconocida en el área andina y un sitio web actualizado constantemente. El IFEA, bajo la tutela del Ministerio de Relaciones Exteriores de Francia, pertenece a la red conformada por 27 institutos franceses de investigación en ciencias sociales y arqueología que se encuentran en el extranjero, distribuidos con sus filiales en 35 ciudades del mundo. Desde 1948, el IFEA ha acogido a 330 investigadores, entre los cuales 85 bolivianos, ecuatorianos, colombianos y peruanos (estas «becas» andinas fueron creadas en 1985), ha coorganizado y/o apoyado más de 100 eventos científicos y ha coeditado aproximadamente 250 obras.

La política científica del IFEA consiste en llevar a cabo investigaciones pluri e interdisciplinarias que se inscriben dentro del marco de la temática general «Los países andinos: multiplicidad de las herencias históricas, diversidad y dinámicas de los medios y de las sociedades» y se organizan en torno a tres grandes ejes estratégicos:

- Mundo andino: patrimonio, herencias, supervivencias (estudios arqueológicos, antropológicos e históricos referentes a la emergencia, el desarrollo y las transformaciones de las culturas, de las sociedades y de los Estados);

- Riesgos naturales, riesgos de sociedad (estudio de los riesgos, mayores y menores, potenciales y efectivos, naturales y de sociedad que afectan a las poblaciones);

- Procesos y formas de integración y de exclusión (investigaciones relativas a los mecanismos de integración y de exclusión, que pueden ser tratados dentro del marco de numerosas disciplinas y abordados a diferentes escalas). 
El primer eje, el «tradicional», reúne las disciplinas fundadoras del Instituto; los otros dos ejes, en relación directa con las realidades contemporáneas de las áreas geográficas cubiertas por el Instituto, se abren sobre las problemáticas actuales de los medios y de las sociedades andinas y latinoamericanas (físicos, políticos, sociales, económicos, etc.) A fines del año 2006, el IFEA cuenta con 23 investigadores —más 7 investigadores asociados- distribuidos en los cuatro países andinos en los que trabaja el IFEA ( 7 en el Perú, 5 en Colombia, 4 en Ecuador, 4 en Bolivia y 3 en Francia). Las disciplinas más representadas son: geografía (5 investigadores), antropología y etnología (4), arqueología (3) y sociología (3). Prosiguiendo e intensificando su política de investigación en cooperación, pues uno de sus objetivos es apoyar a los investigadores y a los estudiantes andinos, el IFEA ha acogido a 8 becarios (4 colombianos, 2 peruanos, un ecuatoriano y un boliviano).

La animación científica permite al investigador presentar sus estudios y su metodología en el marco de conferencias, coloquios y seminarios. En 2006, los ciclos de conferencias organizados por el IFEA, el IRD y las Embajadas de Francia en los locales de las alianzas francesas se han realizado al ritmo de una decena de presentaciones anuales en Bolivia, en Colombia y en el Perú, hechas por investigadores de esas naciones o por franceses, sean o no miembros del IFEA. Desde hace algunos años, el IFEA ha intensificado sus esfuerzos en materia de coorganización y de participación en manifestaciones científicas con instituciones francesas y andinas (universidades, centros de investigación) con el apoyo, entre otros, de las Embajadas de Francia y de las Oficinas de Cooperación Regional —instaladas en las sedes de las Embajadas de Francia en Perú y en Chile-. En 2006, el IFEA ha coorganizado y/o apoyado 21 eventos científicos en los cuatro países andinos: 6 en Ecuador, 5 en Bolivia, 4 en Colombia, 4 en el Perú y 2 en México —organizados por el Centro Francés de Estudios Mexicanos y Centroamericanos (CEMCA), el otro instituto francés implantado en América Latina.

La difusión y la valorización de los conocimientos se basan en una política editorial muy activa. Además de los tres números del Bulletin de I'IFEA, que existe desde 1972 y en el que se han publicado más de 800 artículos, el Instituto ha coeditado 27 obras en 2006 con universidades y centros de investigación andinos: 21 en la colección Travaux de I'IFEA, creada en 1948, y 6 en la serie Actes \&Mémoires, fundada en 2005. Si bien la mayoría de las obras se han publicado en el Perú (11), las filiales no han estado inactivas: 10 obras publicadas en Bolivia, 4 en Ecuador, 1 en Colombia y 1 en Venezuela. Las disciplinas más representadas han sido historia (14 obras), antropología (6) y sociología (3). Esta dinámica política editorial se basa en una sólida red de difusión (intercambios de publicaciones con universidades y centros de investigación, venta a consignación en 25 librerías andinas) y en la participación creciente en las ferias del libro, nacionales, regionales e internacionales (11 en 2006).

Finalmente, últimos eslabones de la cadena científica, la biblioteca y el sitio web del IFEA son herramientas de referencia para los investigadores que trabajan sobre los países andinos. Ambos permiten acrecentar la visibilidad y el alcance del Instituto, no solo a escala regional sino también a escala internacional. Gracias a intercambios, compras y donaciones, el fondo de la biblioteca del IFEA, que recibe anualmente la visita de aproximadamente 2500 lectores, se ha enriquecido considerablemente. Este contiene más de 33000 libros, 42000 números de revistas (300 títulos vivos), más de 1300 tesis (microfichas) sustentadas en Francia sobre América Latina y 1500 mapas. Informatizada desde 1985, la biblioteca ofrece al lector cerca de 150000 referencias bibliográficas que permiten una búsqueda rápida y eficaz. Estas se encuentran en línea en el sitio web del IFEA que ya ha recibido cerca de 70000 visitantes en 2006. Este reúne las informaciones generales relativas a la vida del Instituto, el conjunto de los artículos del Bulletin de I'IFEA, disponibles en formato pdf, un catálogo etnográfico multimedia Las tradiciones orales y musicales de los países andinos comenzado en 2001, etc. Los cuatro elementos del dispositivo cultural y científico en el Perú, que trabajan en estrecha sinergia, son apoyados, en diferentes niveles en función del estatuto y de las misiones respectivas de cada institución, por la Embajada de Francia. 


\section{3. El apoyo de los servicios de la Embajada de Francia}

La Embajada de Francia dispone de algunas herramientas que le permiten participar en el desarrollo sostenible del Perú, en la lucha contra la pobreza y las desigualdades, en el refuerzo del Estado de derecho y en operaciones culturales, científicas y universitarias. Su intervención puede ser directa o indirecta. En el primer caso, su acción se basa sobre medios «ordinarios» limitados, aquellos de los que disponen todas las embajadas de Francia (dotación presupuestal del Servicio de Cooperación y de Acción Cultural [SCAC], del orden de 0,6 millones de dólares anuales y acciones a través de la red de establecimientos franceses y francoperuanos establecidos en el Perú), y sobre medios excepcionales, no renovables: fondo de contrapartida para la ayuda alimentaria, que terminará en junio de 2007 (12 millones de dólares afectados a pequeños proyectos de desarrollo entre 1991 y 2007) y fondo de contravalor para la inversión en el desarrollo sostenible (conversión de deuda de 6,5 millones de dólares afectados al sitio arqueológico de Choquequirao). En el segundo caso, la Embajada interviene a través de contribuciones del Estado francés en los presupuestos de la Unión Europea, de las instituciones multilaterales y de algunas ONG. Finalmente, la Oficina Regional de Cooperación para los países andinos cuya sede está en el Perú dispone de su propio presupuesto.

En los campos cultural, científico, universitario y de cooperación regional, los servicios de la Embajada de Francia desempeñan un rol motor (promoción de la diversidad cultural, de la lengua francesa y de los intercambios científicos y universitarios). Rara vez la Embajada interviene sola pues a menudo la mayoría de sus acciones se llevan cabo en estrecha asociación con los otros actores del dispositivo cultural y científico francés y francoperuano en el Perú, presentados líneas arriba. A veces es iniciadora de un proyecto y puede ser quien lo encabece, a veces acompaña y apoya las acciones efectuadas por otros establecimientos franceses y francoperuanos (Alianza Francesa, IFEA, IRD, Colegio), quienes coorganizan eventos científicos y culturales con instituciones peruanas.

En el campo de la promoción de la diversidad cultural peruana, la Embajada participa o apoya múltiples operaciones, en estrecha asociación con las instituciones locales. Recientemente se ha llevado a cabo varias acciones para valorizar el patrimonio nacional. El programa de puesta en valor del sitio de Choquequirao ha sido realizado en el marco de un acuerdo de conversión de deudas para el desarrollo sostenible entre Perú y Francia. Además de la restauración y la conservación del patrimonio arqueológico del sitio, se trataba de dar inicio a la implementación de equipos turísticos básicos y rehabilitar vías de acceso y caminos. En 2006, la Embajada, que participó en la restauración de órganos históricos de la catedral de Cusco, ha apoyado también proyectos destinados a difundir la cultura peruana en Francia (exposiciones organizadas en París en 2006 en el Petit Palais, Pérou : I'art de Chavín aux Incas, y en 2008 en el Musée du Quai Branly, La culture Paracas). Por último, la Embajada desarrolla sus relaciones con la Biblioteca Nacional del Perú (BNP), cuyos nuevos locales fueron inaugurados en 2006, así como con los medios de comunicación (modernización de la red pública de radio y televisión, por ejemplo).

La promoción de la lengua y de la cultura francesa pasa por el apoyo al Colegio Franco Peruano, a las alianzas francesas y a la Unión Peruana de Profesores de Francés (UNIPPROF) así como a los eventos que estos organizan o co-organizan. En el campo de la creación contemporánea (Pasaporte para un artista y operaciones en el campo de las artes vivas), los servicios de la Embajada promueven y apoyan iniciativas de carácter asociativo con las alianzas francesas y las instituciones locales. También apoyan el debate de ideas (conferencias, coloquios, exposiciones) con el apoyo de la de la comisión del PNUD y de TV Perú. La promoción de la joven creación en el campo de las artes visuales y escénicas y el diálogo entre científicos de ambos países permiten reforzar los intercambios culturales entre el Perú y Francia. La consolidación de estas relaciones, en la que participa el conjunto de los componentes de la Embajada, debe permitir tejer lazos de cooperación aún más estrechos entre artistas y equipos de creación, entre escuelas de arte y universidades francesas y peruanas y entre científicos de ambos países. En razón del aumento regular del número de estudiantes de la lengua francesa, se han implementado formaciones 
universitarias innovadoras y conducentes a un diploma en Francés Lengua Extranjera (FLE), se ha enviado a establecimientos franceses a asistentes de lengua y se han emprendido acciones en relación con el Centro Internacional de Estudios Pedagógicos (CIEP).

Desde hace algunos años, la Embajada ha desarrollado mucho sus acciones en asociación con las universidades peruanas y con los actores locales de la investigación al servicio del desarrollo, en estrecha colaboración con los institutos franceses establecidos en el Perú. En 2006, varios acuerdos importantes han sido firmados: un acuerdo-marco con el CONCYTEC, asociando al IRD y al IFEA, y un acuerdo específico que permite publicar en castellano artículos de la revista Futuribles; acuerdos de operación entre universidades de excelencia públicas (la Alianza Estratégica para el desarrollo de la educación superior agrupa a la Universidad Nacional Agraria de La Molina, a la Universidad Nacional de Ingeniería y la Universidad Nacional Mayor de San Marcos) y privadas (Pontificia Universidad Católica del Perú-PUCP y Universidad Ricardo Palma). La Alianza Estratégica ha permitido en particular implementar un fondo iniciativo multipartenarial de becas doctorales (fondo semilla) que debe contribuir a la formación de estudiantes (nivel maestría y doctorado), a la constitución de grupos de investigación y a la asociación de equipos. Esta política será reforzada en 2007, con el apoyo de la Asamblea Nacional de Rectores (ANR), abriéndose hacia el norte (Trujillo) y el sur del país (Arequipa): una universidad de cada una de estas regiones encabezará a estos dos subconjuntos. Además, las oficinas de EduFrance instaladas en las alianzas francesas de provincias serán consolidadas.

Instrumento privilegiado de la cooperación interuniversitaria francoperuana desde el año 2000, la Red Raúl Porras Barrenechea (RPB) agrupa a 15 universidades francesas y 18 peruanas (medio centenar de acuerdos interestablecimientos se habían firmando en 2006 contra 10 en 2000, año de la creación de la red). La convención constitutiva del RPB ha sido renovada por cinco años en 2006; apoyada por la ANR, el CONCYTEC y la Conferencia de Presidentes de Universidades (CPU), el IFEA, el IRD y la Alianza Francesa están ahora asociadas a la RPB, coordinada por la PUCP y la universidad de Burdeos IV. Esta red está destinada a favorecer la unión entre formación e investigación, la implementación de redes temáticas, la movilidad de los estudiantes de ambos países privilegiando a aquellos que emprenden una maestría o un doctorado en codirección o co-tutela, la implementación de cátedras y la articulación con las herramientas de la cooperación bilateral (Comité: Evaluación-Orientación de la Cooperación Científica [ECOS]), regional (Programa regional Francia-América Latina-Caribe [PREFALC], Programa de Cooperación Postgrado [PCP] Países Andinos) y multilateral (programas ALßAN). Estos programas, que ofrecen becas de formación de alto nivel, buscan reforzar la cooperación en el campo de la educación superior: están destinados a estudios de tercer ciclo así como a formaciones de alto nivel, para profesionales latinoamericanos, en instituciones o en centros de los países de la Unión Europea, entre ellos Francia.

Estos esfuerzos sostenidos han llevado al aumento continuo del número de estudiantes peruanos que prosiguen sus estudios en Francia (un poco más de 300 en 2000, 573 en 2005 y 608 en 2006 - de los cuales más de la mitad en maestría y doctorado — sin tomar en cuenta los ingresos e inscripciones de peruanos en las «grandes escuelas» y en las escuelas superiores de comercio y de ingenieros) y al de los profesores peruanos invitados a Francia (aproximadamente 80 en 2005 y 120 en 2006). Apenas $6 \%$ de los peruanos que estudian en Francia (36) se han beneficiado de una beca de estudios del gobierno francés conducente a la obtención de un diploma: si la mayoría asume los gastos de sus estudios, cabe destacar que el sistema universitario francés (módicos derechos de inscripción, facilidades de alojamiento, acceso a la cobertura social) es competitivo frente a las condiciones de acceso a la enseñanza superior en otros países del continente americano... incluso en el Perú.

Con el apoyo de otras instituciones culturales y científicas en el Perú y en asociación con instituciones peruanas, la Embajada participa en la organización y en la financiación de premios de audiencia nacional: Premio Franco Peruano Raúl Porras Barrenechea para la formación doctoral, destinado a los docentes peruanos de las universidades públicas y privadas, atribuido dentro del marco del RPB; Premio Franco Peruano para la promoción de la formación técnico- 
profesional y de la innovación tecnológica; Premio François Bourricaud al joven investigador en ciencias sociales. El IFEA, la Embajada de Francia en el Perú, el IRD, la Alianza Francesa, el CONCYTEC, la Red para el Desarrollo de las Ciencias Sociales en el Perú y el Instituto de Altos Estudios de América Latina (IHEAL) han creado en 2004 el Premio François Bourricaud. Destinado a los investigadores peruanos de menos de 35 años, este premio busca recompensar un estudio académico en antropología, sociología, historia o ciencias políticas. El IFEA, que ha tomado la posta de la Embajada en 2006, se encarga de la organización de este evento. La ganadora de 2006 viajará a Francia en el próximo mes de marzo para efectuar una misión a cargo de las instituciones organizadoras.

La Oficina de Cooperación Regional francesa para los países andinos, cuya área de acción cubre los países en los que trabaja el IFEA y Venezuela, ha sido transferida de Bogotá a Lima a fines del año 2005. Este cambio, que se justifica por la ubicación de la sede de la Comunidad Andina (CAN) en el Perú, ha permitido acrecentar la influencia del servicio de cooperación regional. Además del importante apoyo a las acciones regionales llevadas a cabo por el IFEA y el IRD (participación en coloquios y en coediciones de interés regional, Estado de derecho, dinámicas migratorias, nueva arquitectura de los poderes locales, reconocimiento de las minorías...), la misión principal del servicio de cooperación regional es la de acompañar la construcción de la integración andina conforme al Acuerdo de Cartagena firmado en 1969. Los ejes de cooperación privilegiados coinciden con los intereses de los otros servicios de la Embajada de Francia: diversidad cultural, defensa de la biodiversidad, nuevo paisaje institucional producto del proceso de descentralización, implementación de normas estadísticas comunitarias, seguimiento de los acuerdos de complementariedad entre la CAN y el MERCOSUR. Estos programas se conducen junto con la Secretaría General de la CAN y la del Parlamento Andino, el Convenio Andrés Bello y la organización Andina de Salud. Finalmente, gracias a dos servicios que dan consistencia a sus compromisos — la acción audiovisual y la cooperación jurídica y judicial— la Cooperación Regional Andina interviene en estrecha colaboración con cada uno de los servicios de cooperación y de acción cultural sobre temas fundadores que atraviesan el espacio andino: salvaguarda de los archivos audiovisuales, implementación de la ayuda mutua judicial, lucha contra la corrupción y las nuevas prácticas criminales, etc.

\section{A MANERA DE CONCLUSIÓN: ¿CUÁL SERÁ EL FUTURO?}

A pesar de los limitados medios presupuestales, el dispositivo de cooperación francesa en Perú se caracteriza por su coherencia y su dinamismo y todos sus elementos trabajan en perfecta sinergia. Este permite continuar asegurando una fuerte presencia intelectual y científica francesa en Perú, que contrasta con el rol marginal de Francia en la economía peruana y la escasez de sus inversiones. Los próximos años prometen ser ricos en los campos cultural, científico y universitario: los acuerdos interuniversitarios son sólidos y los mecanismos de cooperación en la enseñanza superior y la investigación están muy experimentados; los proyectos son ambiciosos (creación de la Casa Franco Andina de investigación, plataforma conjunta de trabajo Embajada de Francia-IFEA-IRD que permitirá acoger investigadores y catedráticos franceses sea cual fuere la institución para la que trabajan); los dos institutos de investigación instalados en Perú organizarán manifestaciones de envergadura con ocasión del aniversario de su presencia en el Perú (40 años en el caso del IRD en 2007 y 60 años el IFEA en 2008).

Dentro del contexto peruano de estabilidad política y de crecimiento económico, parece que Francia puede mejorar su posición económica en Perú. Sin embargo, aunque América Latina sigue siendo un área geográfica a la que Francia da importancia, ella no es su prioridad. Las recomposiciones políticas, económicas y territoriales dentro del contexto de internacionalización de los intercambios y de la globalización así como el legado de la colonización explican, por un lado, el interés creciente de Francia por la antigua Europa del Este, de la cual numerosos Estados hoy son parte de la Unión Europea, y por China e India, en menor medida; por otro 
lado, el interés histórico por África occidental y la región del Magreb. Además, en América Latina económicamente hablando algunos países o regiones son más atractivos que el mundo andino, así los «grandes países» (México, Brasil) y el Cono Sur. Finalmente, en el seno del espacio andino, los intereses económicos de Francia están mucho más presentes en Colombia en el norte y en Chile y en Argentina en el sur, que en Perú o que en Bolivia. A inicios del siglo XXI parece muy difícil invertir esta tendencia de manera significativa.

Si los resultados obtenidos por Francia en los campos cultural y científico en América Latina en general, y en Perú en particular, son positivos, no obstante es preciso relativizarlos. A escala de Europa, las partidas presupuestarias asignadas por Francia a la cooperación en América Latina - a semejanza de otras regiones del planeta- siguen estando muy por debajo de los recursos asignados por otros miembros de la Unión Europea. A escala francesa, África y la región del Magreb están muy favorecidos y Asia está en general en crecimiento... aunque modesto. Como muestra tres ejemplos. De los 27 institutos de investigación franceses en el extranjero que dependen del Ministerio de Relaciones Exteriores (MAE), solo 2 se encuentran en América Latina. Si la representación del IRD en el Perú es la segunda del subcontinente, después de la de Brasil, cerca de $60 \%$ de los investigadores, ingenieros y técnicos del Instituto destacados al extranjero están instalados en los países de la zona África/Mediterráneo; 30 \% tienen puestos en América Latina, área geográfica que está muy por delante de la zona Asia/Pacífico. Por último, 3,4 \% de los estudiantes extranjeros inscritos en las universidades francesas en 2005-2006 eran oriundos de América del Sur, contra 49 \% de África (los ciudadanos de la región Asia/Oceanía, en fuerte crecimiento desde el año 2000, representaban 13,6\% del total). El Perú ocupaba la sexta posición después de Brasil y Colombia (más de 2 000), México, Argentina y Chile con quien el Perú empataba (619 contra 608).

En estas condiciones, los resultados obtenidos por Francia en el Perú son aún más meritorio. Sin embargo, se puede temer que en el contexto francés actual de restricciones presupuestarias y de relativa pusilanimidad, la tendencia sea al repliegue sobre las regiones geográficas «tradicionales» y a los intentos de avanzadas hacia aquellas que son más atractivas. Estas tendencias pesadas, a escala nacional, no favorecen los campos cultural, científico y universitario. En el Perú, la escasez del tejido de las empresas francesas impide al sector privado venir en apoyo de las acciones culturales y científicas. La creación en 2006 de la Fundación Franco Peruana por la Embajada de Francia es un elemento positivo que completa el dispositivo existente. Sin embargo, esta nueva herramienta descansará sobre un melenado esencialmente peruano: en razón de sus limitados recursos no podrá completar la acción pública. Garantizará el apoyo a programas innovadores que la cooperación multilateral o bilateral no puede asumir y será seguramente eficaz para movilizar recursos en el Perú en la perspectiva del año de América Latina en Francia en 2010-2011.

\section{Referencias citadas}

ALLIANCE FRANÇAISE, 2006 - Alliance française; Lima: Alliance française. Fichier PowerPoint. AMBASSADE DE FRANCE AU PÉROU, MISSION ÉCONOMIQUE DE LIMA, 2005a - Les échanges bilatéraux entre la France et le Pérou, 3 p.; Lima: Ambassade de France.

AMBASSADE DE FRANCE AU PÉROU, MISSION ÉCONOMIQUE DE LIMA, 2005b - Les échanges commerciaux de la France avec le Pérou et la Bolivie en 2004, 3 p.; Lima: Ambassade de France. 
La presencia francesa en la economía y la sociedad peruanas

AMBASSADE DE FRANCE AU PÉROU, MISSION ÉCONOMIQUE DE LIMA, 2005 - Implantations et/ou participations des entreprises françaises au Pérou, 9 p.; Lima: Ambassade de France.

AMBASSADE DE FRANCEAU PÉROU, MISSIONÉCONOMIQUE DE LIMA, 2005-Investissements français et présence française au Pérou, 2 p.; Lima: Ambassade de France.

AMBASSADE DE FRANCE AU PÉROU, MISSION ÉCONOMIQUE DE LIMA, 2006 - Le commerce extérieur du Pérou et de la Bolivie en 2005, 3 p.; Lima: Ambassade de France.

AMBASSADE DE FRANCE AU PÉROU, MISSION ÉCONOMIQUE DE LIMA, 2006 Investissement direct étranger et présence française au Pérou et en Bolivie en 2005, 3 p.; Lima: Ambassade de France.

AMBASSADE DE FRANCE AU PÉROU, MISSION ÉCONOMIQUE DE LIMA, 2006 - Les échanges commerciaux de la France avec le Pérou et la Bolivie en 2005, 4 p.; Lima: Ambassade de France.

AMBASSADE DE FRANCE AU PÉROU, MISSION ÉCONOMIQUE DE LIMA, 2006 - Documents internes.

AMBASSADE DE FRANCE AU PÉROU, SERVICE CONSULAIRE, 2004 - Note sur la communauté française, 4 p.; Lima: Ambassade de France. Document interne.

HUET, P. D, 2004 - Diana de Castro o el falso Inca, 132 p.; Lima: Ambassade de France, Fondo editorial Universidad nacional mayor de San Marcos, IFEA, Lluvia Editores. Traduction d'un manuscrit en français de 1667.

INSTITUT FRANÇAIS D'ÉTUDES ANDINES, 2006 - Presentación-2006; Lima: IFEA. Triptyque.

INSTITUT FRANÇAIS D'ÉTUDES ANDINES, 2006 - Documents internes.

INSTITUT DE RECHERCHE POUR LE DÉVELOPPEMENT, 2006 - Rapport annuel de I'IRD 2005, 60 p.; Paris: IRD.

INSTITUT DE RECHERCHE POUR LE DÉVELOPPEMENT, 2006 - Documents internes.

LEFORT, D., POUPON, H., SAINT-GEOURS, Y., 1988 - La investigación francesa y el Perú, 107 p.; Lima: IFEA, Orstom.

LYCÉE FRANCO-PÉRUVIEN, 2006 - Documents internes.

MINISTÈRE DES AFFAIRES ÉTRANGÈRES (MAÉ), 2006 - Mobilité internationale des étudiants et attractivité de la France, Amérique, n.p.; France. Rapport interne.

MINISTERIO DE ECONOMÍA Y FINANZAS, DIRECCIÓN GENERAL DE ASUNTOS ECONÓMICOS Y SOCIALES, 2001 - Hacia la búsqueda de un nuevo instrumento de focalización para la asignación de recursos destinados a la inversión social adicional en el marco de la lucha contra la pobreza, 64 p.; Lima: Ministerio de Economía y Finanzas.

NOVAK, F., 2005 - Las relaciones entre el Perú y Francia (1827-2004), 321 p.; Lima: Embaja de Francia, Pontificia Universidad Católica del Perú.

SUPERINTENDENCIA NACIONAL DE ADMINISTRACIÓN TRIBUTARIA (SUNAT), 1999-2006 Anuarios estadísticos, moteur de recherche par pays et région géographique sur le site de la SUNAT; Lima: SUNAT.

\section{Sitios Internet consultados}

AGENCE POUR L'ENSEIGNEMENT FRANÇAIS À L'ÉTRANGER: http://www.aefe.diplomatie.fr/ aefe/texte.nsf/pageaccueil?readform

ALLIANCE FRANÇAISE (SIÈGE-PARIS): http://www.alliancefr.org/

ALLIANCE FRANÇAISE (PÉROU): http://www.alianzafrancesalima.edu.pe/

AMBASSADE DE FRANCE AU PÉROU: http://www.ambafrance-pe.org/ 
AMBASSADE DE FRANCE AU PÉROU-MISSION ÉCONOMIQUE DE LIMA: http://www. missioneco.org/perou/

ÉDUFRANCE: http://www.edufrance.fr/

INSTITUT FRANÇAIS D'ÉTUDES ANDINES (IFEA): http://www.ifeanet.org/

INSTITUT DE RECHERCHE EN COOPÉRATION (IRD): http://www.peru.ird.fr/rubrique_accueil. php3?id_rubrique $=153$

LYCÉE FRANCO PÉRUVIEN: http://www.Ifrancope.net/

PROINVERSIÓN: http://www.proinversion.gob.pe/

SUPERINTENDENCIA NACIONAL DE ADMINISTRACIÓN TRIBUTARIA: http://www.sunat.gob.pe/ 